\title{
Digital Tom Thumb. A digital mobile and geobased signage system in public spaces orientation.
}

\author{
Letizia Bollini, $\mathrm{PhD}$ \\ Department of Psychology, University of Milano-Bicocca \\ Piazza dell'Ateneo Nuovo 1, 20126 Milano, Italy \\ letizia.bollini@unimib.it
}

\begin{abstract}
The paper presents an experimental project of a digital mobile and geobased signage system applied to a public space - the University of MilanoBicocca Campus - and to a digital information tool aimed to guide the choices of students in choosing their university career and to support them along the experience (called the Students' Guide). The project approaches all the information, services, tasks and the interaction both with the external environmental findability and orientation supported by GPS and geobased data - and internal spaces - localization and information inside the building supported by Beacon technology - according to a digital ecosystem design approach. The app MoBi Moving in Bicocca. Digital Pollicino (Moving in Bicocca. Digital Tom Thumb) has been designed, prototyped, tested, revised and validated thorough the user-centered approach, co-design and qualitative research methods. Although applied to a specific case study - the whole campus and the building U6 of Milano-Bicocca University - the research approach and the systemic perspective are intended to be replicable as a design frame-work.
\end{abstract}

Keywords: geobased interaction design, geobased mobile app, mobile app design, mobile app user experience, Beacon, digital signage.

\section{Social geographies and cognitive dimensions}

According to the studies of La Cecla [1] it is possible to classify two kind of orientation approaches developed to interact with a place: the topographic orientation that uses quantitative and absolute measurement units to define spatial relations, and a relative orientation - a sort of egocentric point of view - that has the subject in itself as the epicentre of spatial distribution.

On the other hand places themselves have a story-telling vocation and intention (see the work of Floriani about the Grammar of Communication [2]) that allows people - both as individuals and as groups - to build collective mental models and shared maps of the space they interact with according to Lynch's work The image of the city [3].

To surf through and unknown space - both physical and cognitive has underlined by Wurman [4] in his information architecture studies about urban and web environment - activates two different relational modalities: orientation and navigation. The first need is to understand were we are and how the surrounding is related to us, 
where we come from and in which directions we can further proceed. The second is to explore, to discover, to know and understand the place for building a mental model to refer to in the next interactions, the so-called cognitive mapping.

In return the environment could have good topological and eidetic categories or a visual and perceptual homogeneity, on one hand, or a deep environmental overload that interferes with the creation of a clear image of it as expressed by Augé in his well-known philosophical essay about the non-lieu [5].

Identity, structure and meanings determinate the ability of people to move or better to say - to interact with the space in a sort of aporetic process in which experience has been acquired through experience. The process is a progressive addition in terms of space and time that implies to generate both perceptual and cognitive dynamics according to Ittelson's theory [6]

If the interaction with a physical space implies so many individual and social construction that means individual and collective images, shared knowledge and symbolic culture of the community that inhabit in it a further exploration can give significant insight on geobased information and the connection built among them, people and their spatial relation.

Intercepting these shared images could give a significant insight both individual and collective of the mental models that people share which are the cognitive maps and semiotic meanings emerging from the space with/in which they interact.

Consequently - to you this images as a driver of planning and communication activity - it is important to identify a way to discover how they are socially and individually built. The culture of psychological geography suggest some direct and implicit methodologies to use in the field research and directly when working with users. The work of Bagnara and Misiti [7] collects and presents some theoretical positions and an experimental research based on a qualitative, hybrid approach to people relational and cognitive connection with city's environment.

\section{The cognitive and spatial perspective on orientation}

\section{Representative test}

This social representation of the space is well emerged by a first experimental approach and user testing activities on different segmentation of students population to identifies possible differences among them.

One of the first issues, according with the whole research plan, has been to map and analyse the user needs, the strategies adopted and the tools considered useful in such a circumstance that involves a long-term decision with huge consequences in the future.

A first qualitative recognition has been conducted defining the main user personas, archetypical users arise from research. During this recognition phase volunteers were asked to respond to an interview aimed to understand the level of knowledge both of the academic offers and the Bicocca Campus. Then their were asked to use their memory and previous experience to draw a neighbourhood map according to a quali- 
tative representative method presented in the work of Francescato and Mebane [8] and already adopted and discussed at ICCSA Conference in 2011 [9]. Finally they were asked - according to a user test task-based approach - to find critical places and services describing their cognitive strategies and choices expressing aloud their thought (thinking aloud method).

All the results, answers and paths were recorded, analysed and compared to identify common behaviours, problems and recursive patterns. The main tasks were designed or adapted according to a previous experiment conducted in the same area in 2006 - as presented at the VIII Colour Conference in 2012 [10] - to have a comparative benchmark.

\section{Spatial user test task-based and persona}

The collected data were used to build persona and user-scenarios. A set of taskbased user test were conducted according to the hypothesis on target segmentation beside questionnaire and representative methods were used to collect more insight on mental models built by people and difficult emerging in exploring and finding way in a complex environment.

A first group is represented by high-school students, which come to the Bicocca Campus for the first time during the open days. In spring time the universities organize some activities to promote master and degree courses to involve potential clients in a marketing and advertising campaign to directly grab the best and more motivated students before the admission tests to be held in early September.

This group has been clustered and described by the newbies label. They are 18/19 years old, not yet familiar with some of the structural and formal requirements and fulfilments of the university world. They do not know the Bicocca Campus and need some extra support in orientation both in the physical space and in the log-term decision about university career.

A second group is the so-called intermediate: age 22, they have already a first level degree and are aware of university procedures and bureaucracy, but unfamiliar with the Bicocca Campus because coming from another athenaeum or from another city.

The third segment is represented by Gurus: people between 22 and 24 years old, that have been attending the Bicocca Campus from the beginning of their career. They are well informed both on academicals fulfilments and of the space of the neighbourhood, not only the campus.

According to recent literature — see the studies conducted by Perkins [11] and in more recent time by Schmidt \& Hawkins [12] about Millenials - they are already considered digital natives. Newbies, Intermediate and Gurus have a massively use of mobile devices $(98,5 \%$ of involved subjects) - at least a smartphone - social networks - Facebook and Snapchat — and instant messaging — whatsapp - and often helps themselves with georeferenced applications: Maps or Google Maps.

A first in field research $i B i$ - conducted in 2014 to understand problems and potential targets of the Students' Guide of the Department of Psychology to promote its courses - gave a first insight of their information retrieval strategies and the use of technological infrastructure in orientation activities both when they are intended to 
take decisions about their university and professional futures and in a way-finding activity in the space of the Campus.

According to user-testing qualitative methodologies developed in user-centered design — see the work of Budiu \& Nielsen [13], and Krug [14] — and their declination in geographical psychology research investigated by Bagnara [7] — an experimental activity was conducted on a segmented panel of users. Subjects -9 for each category - were previously asked to prepare themselves to the spatial tasks finding information (see figure 1 and 2 for indoor and outdoor orientation strategies) and then after a couple of days - to complete a list of spatial activities shaped on their Campus or daily students' life experience out- and in-doors (see figure 3 on data retrieval strategies).

The given tasks to complete were:

1. to get to building U6 from train station or other interconnection points to reach the Aula Magna where courses will be presented;

2. to identify the students' secretariats where to register for the admission test;

3. to visit a professor in his/her room;

4. to find the bar and the canteen where to have coffee-break and lunch;

5. to find the eco-bus stop to go to U16 for English test;

6. to discover facilities linked to students life: copy services and book-shops;

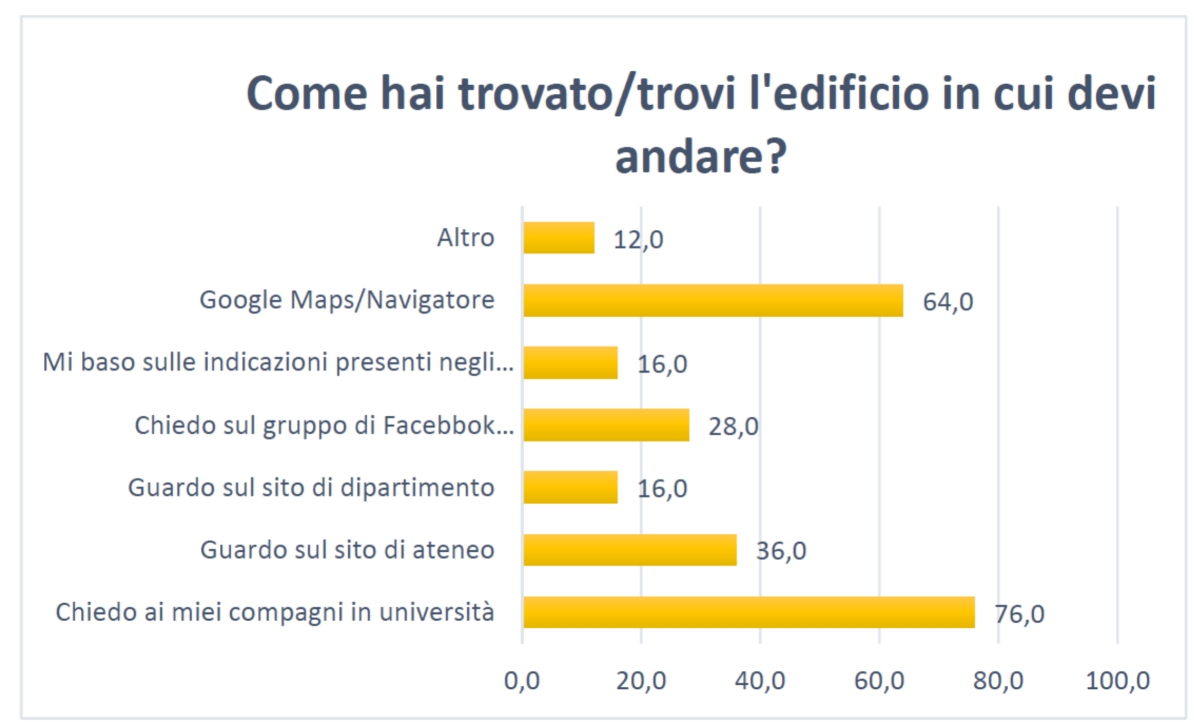

Fig. 1 Outdoor orientation: Strategies used to identify and get to a specific building 


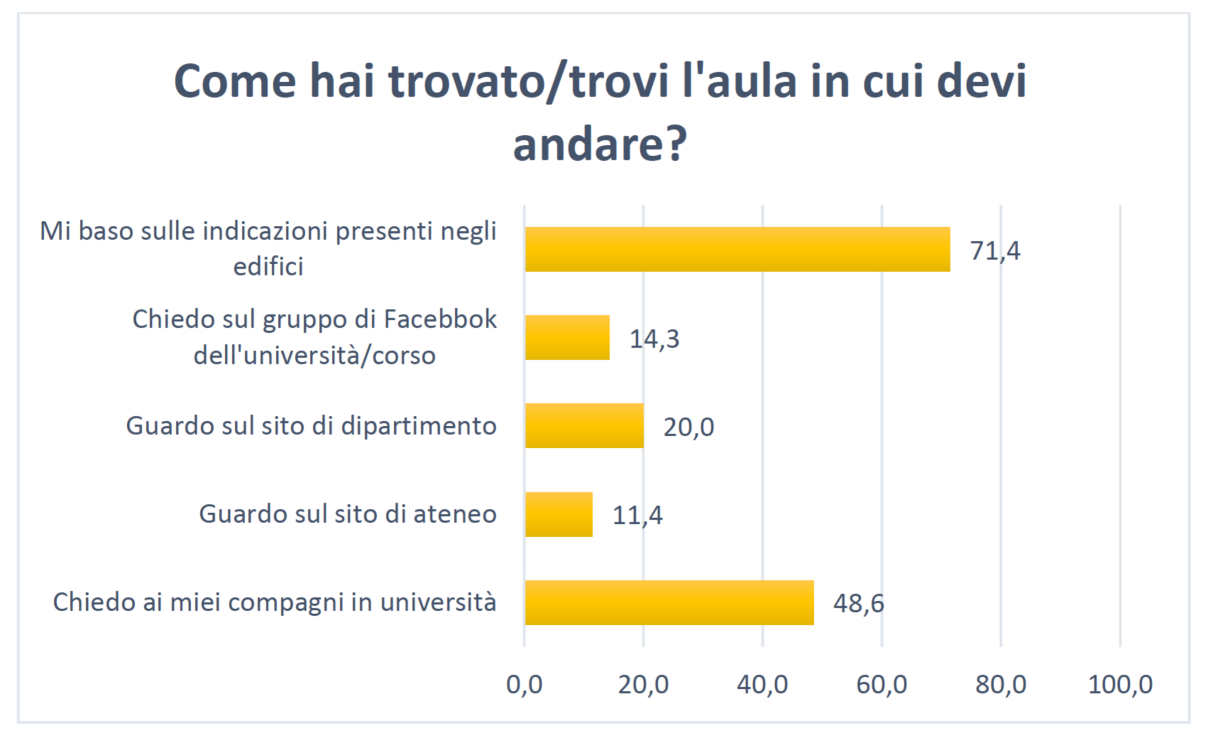

Fig. 2 Indoor orientation: Strategies used to identify and get to a specific classroom

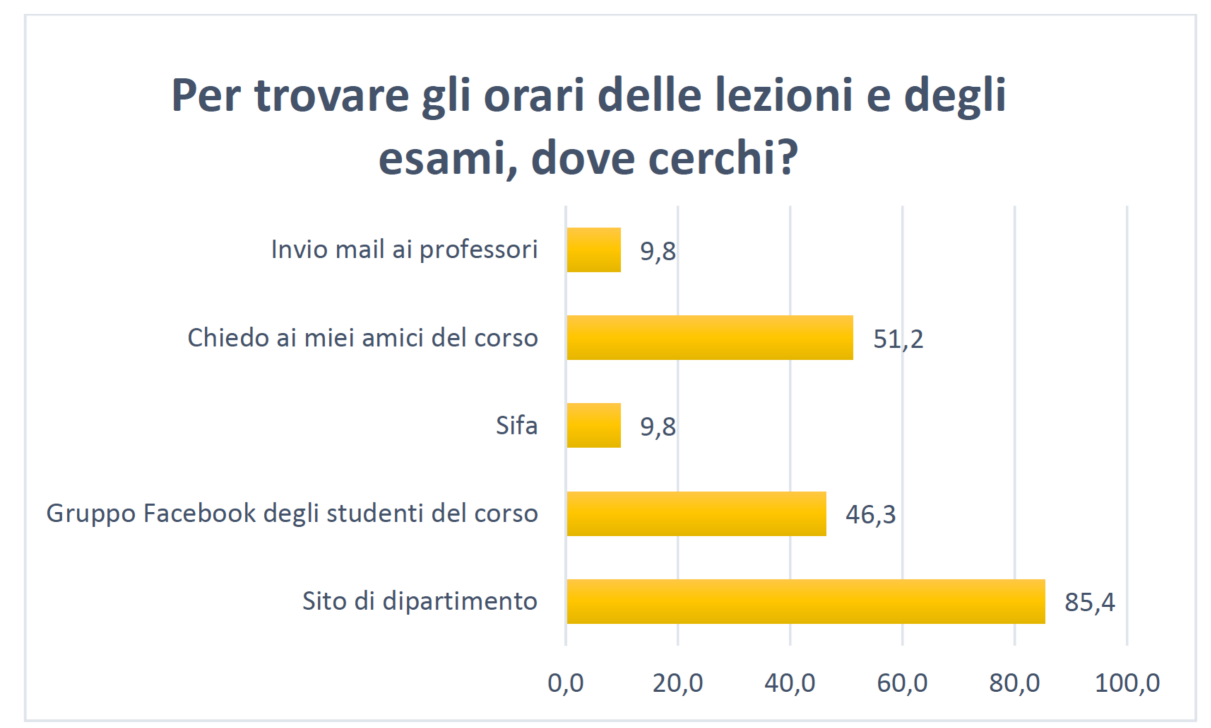

Fig. 3 Information retrieval: Strategies used to find practical information 

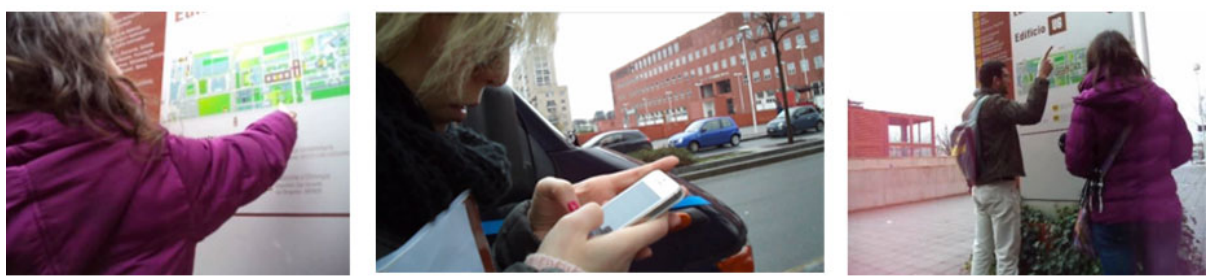

Fig. 4 Newbies: orientation strategies to complete spatial and way-finding tasks outdoor.
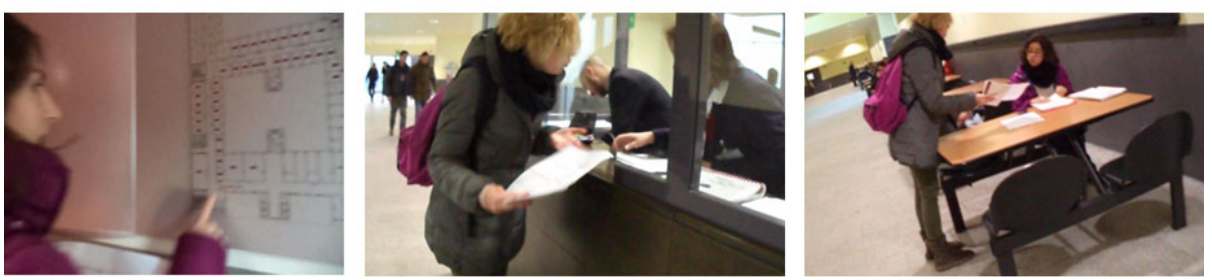

Fig. 5 Newbies: orientation strategies to complete spatial and way-finding tasks indoor.

What emerges from this first task-based spatial user tests sessions is the difficult to identifies a clear mental model of the space around them - bot outdoor and inside the single building. The place has an overall lack of figurability - or environmental layout - small and not well-differentiated landmarks and visual anchor-points according to the legibility described by Weisman [15].

Signage elements are not enough to identify the correct or shorter pathway to the final destination and not always present in crucial point where clearer information were needed. Sometimes they are neither updated nor corresponding to real configuration and location of offices and students' services.

Clustering the tasks in order of criticality to define a clear design goals ranking.

Relevant problems: people were unable find the eco-bus stop - task 5-and subjects took more than 40 minutes to find some information about it on the university web site. Signs, maps and other elements located in the space have not at all or incorrect directions. This task was critical also for gurus that already have a good familiarity with the campus structure and services.

Intermediate problems: people were able to find students' offices - task 2, 3 and 6 - just asking to information desks or to other students (see figure 4 and 5). Internal signage and wall-maps do not give such information. Moreover, the inner space lacks of visual anchors or orientations elements so that people start moving around with no idea and find by chance the right destination in a sort of pervert serendipity effect.

Low-level problems: task 1 and 4 were completed almost easily asking to other people or moving according to the critical mass displacements. 


\section{The digital dimension of spatial interactions}

Looking from a technological perspective, it is important to remark that second generation and 3.0 web and mobile application connect deeply the spatial and the social dimension of interactions.

First generation was mainly aimed to give operative GPS instructions such as where the users were, how to move, or to arrive in a specific place showing this date on a map as well exemplified bay iOS Maps ${ }^{\circledR}$ and Google Map ${ }^{\circledR}$ for mobile. Second generation is represented by the use of GPS date and geolocated information to connect people to each other according to a spatial and in presence criteria: the archetype is Four Square ${ }^{\circledR}$. In this case people are able directly interact with the place thanks to the check in task, to see other person on a map, interact with them personally or using social dynamics — such as the major challenge- leaving traces, suggestions, information (user-generated) or notes through the tips features.

\section{Open air and indoor orientation digital supports.}

Among the many technological solutions available on the market an analysis on pros and cons has been conducted to understand and choose a best practice applicable to the project. For a deeper discussion on the issues Manh Hung presents an interesting comparison table about indoor navigation system, although not so updated to the contemporary state of the art. [16]

Following this categorization the research has been expanded to two main issues: the indoor navigation apps - Google Indoor, Apple e Wi-Fi SLAM and Nexton have been identified, analysed and evaluated - and Internet of Things and Smart Tagging technologies.

In particular QR-Code, RFid/NFC and Beacon were considered.

$\mathrm{QR}$-codes - then used as a second choice support in some of the digital signage system - were originally discarded. It seemed that they are not so digital to be included as an efficient support in an IoT approach to spatial interactions. Nevertheless they have been restored and integrated in the final version to support non-Android devices -in this first version of the app - or older devices non compliant with contemporary solutions. Moreover the project was intended to break down barriers between physical and virtual giving a totally trasparent experience to the users.

On the other hand only the Android mobile devices and Windows phone are equipped with Bluetooth 4.0 required by Beacon. This latter technology enable a oneto-many experience generating a direct interaction and feed-back on the user device when in proximity. The notification push system is, surely, very efficient, but, at the same time, very invasive and, potentially, disturbing, giving the user a bad feeling to be under control. However it allows people mot to miss information, help and support in very complex, crowded or spatially confused situations.

NFC, nevertheless, are spreading in commercial context and other public spaces such as museums and other cultural institutions. The communication is one-to-one and directly controlled by the user who must be very closed the NFC tag and intentionally decides to interact with the digital environment. The potentiality of this sys- 
tem consists mainly in the possibilities to be used as payment thechonologies directly connected to banking on line services.

\section{MoBi-Digital Tom Thumb: a mobile context-aware app.}

\section{The spatial scenario and the context aware approach}

Mobile technologies can be, then, a support in facilitating way-finding strategies thanks to the direct relation with geobased data and the physical environment.

At the same time in a complex spatial system such as a university campus related to a peripheral and peculiar neighbourhood - for a wider comprehension of the specificity of the Milano-Bicocca suburb the urban island see the work presented at ICCSA 2011 in Santander [9]- a context-aware application could help and support efficiently the users in their exploration activities.

Among the many definition and theoretical elaboration of the concept, the contextaware system is, here, intended as described by Dey: "Context is any information that can be used to characterize the situation of an entity. An entity is a person, place, or object that is considered relevant to the interaction between a user and an application, including the user and applications themselves" [17]. Besides, Dey underlines how this means that every situation is relevant for the system and its users. Consequently, information and context are dynamic factors. Furthermore Chen and Kotz [18] describe the context as "the set of environmental states and settings that either determine an application's behavior or in which an application event occurs and is interesting to the user."

A final refinement of the idea of the relationship between the space ant the interaction with users comes from the work of Schmidt, Beigl and Gellersen There is more to context than location [19] suggesting that context is made from human factors the social environment, user's identity and tasks - and physical landscape intended as the system of places, environmental conditions and infrastructures. A way-finding approach, according to the conceptual framework of spatial findability developed by Morville [20], therefore could be successfully applied both to this spatial and digital environmental model.

\section{The Beacon plan: contextually and proximity interactions}

The challenge of the project is to develop a user experience completely transparent in the transition between inside and outside space so that people remain focused on the orientation interactions focused on spatial and personal decision-making.

As emerged in the preparatory study, inside the buildings people do not have the support of GPS functionalities and are forced to interact with not-updated printed signs or asking to information desk or other students. Although Google makes available outdoors and indoors API for Google Maps, university campus are considered 
sensible targets so that taking photos or publishing interoperable internal floor-plans of buildings is not allowed.

According to previous consideration about the support of technologies for indoorinteractions and facing the constrains given by the specificity of the place and its security issues, the application uses Beacon and Bluetooth as micro-localization facilitators. They were used both to enable the users' interaction with contextual information connected with their positioning inside the building and to activate or deactivate the out/in-door navigation flow switching from GPS and Wi-Fi + Beacon.

A background location layer is provided by Google Maps ${ }^{\circledR}$ API and its digital cartography support to create, map and align the personalized floor-plans with the image of the building itself. The next operation consists in the mapping activity give place to makers and relative Wi-Fi hot spots and Beacons to have an performing repeaters network validated through Google Maps ${ }^{\circledR}$ Floor Plan Marker [21], to have an effective geolocated-data map (see figure 6 where the experimental infrastructure is spatially described and positioned).
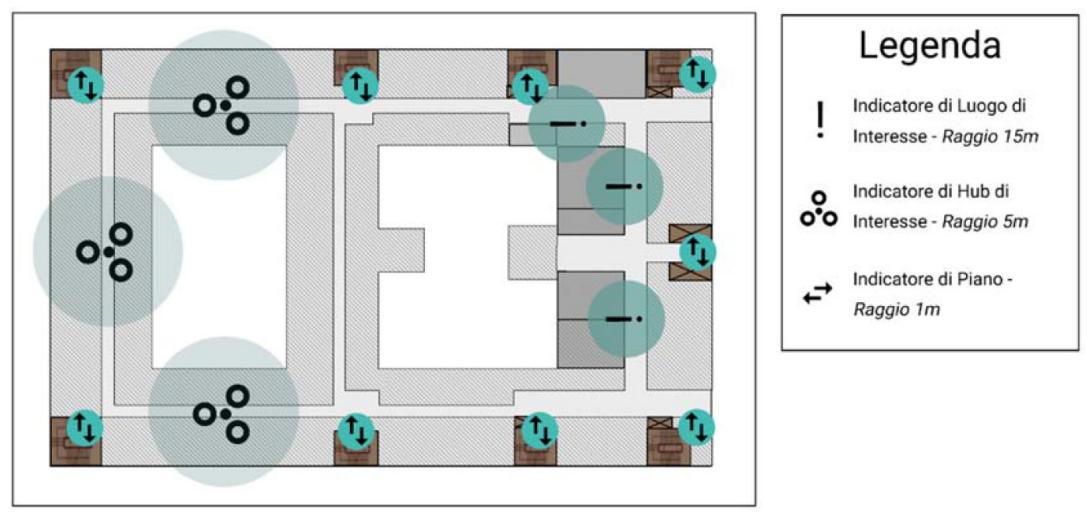

Fig. 6 Beacon plan: positioning hypothesis inside $3^{\text {rd }}$ floor of building U6.

The services and experience delivered by $M o B i$ are not only geolocated, but also context aware and situated, relevant for the user and the tasks that he/she is intending to complete, according to Coutand researches on Contextual Personalised Applications [22] where context itself is part of the information and part of the fruition modalities of data and functions of the application.

According to Schmidt's working model [23] the contest is made by the Physical Environment - the sum of the place, environmental conditions and the infrastructure - and by the Human Factors - that means the social environment, the identity and the tasks to be done by the user- and a temporal structure. Therefore the MoBi app and the digital located infrastructure supports students in the way-finding processes both orienting people through the physical space - the whole Campus, the single building and its inner space-, the information offer according to users' needs mainly common, but with different levels of access according to the persona: seniority, degrees and majors - organized in a timeline - news, reminders and alerts of the university life-cycle. 


\section{Point of interest: interacting with the digital signage plan}

Following the context-aware approach, Beacon where placed along the inner space of the building - paying attention that they signals do not interfere one to another- in the point of interests emerged during the first research phase.

They are: access point to the building, access point to single floor, single point of interests and hub of interest where many spatial functions cross or overlap.

Every point of interest signal is composed by three modules (as shown in figure 7), each one using a specific technological support:

1. contextual element (beacon): information give are the name of the place office, number of the room etc. - and the Beacon showing the Point of interest sign. It uses both the analogic and the digital modality.

2. information element: dynamic, specific and time-based information are displayed chronologically — such as news, time schedule, updated informationscrolling on the display of a tablet

3. documents element: a grid of NFC tag and QR-code is displayed connecting users to URL where to download documents, files and forms.

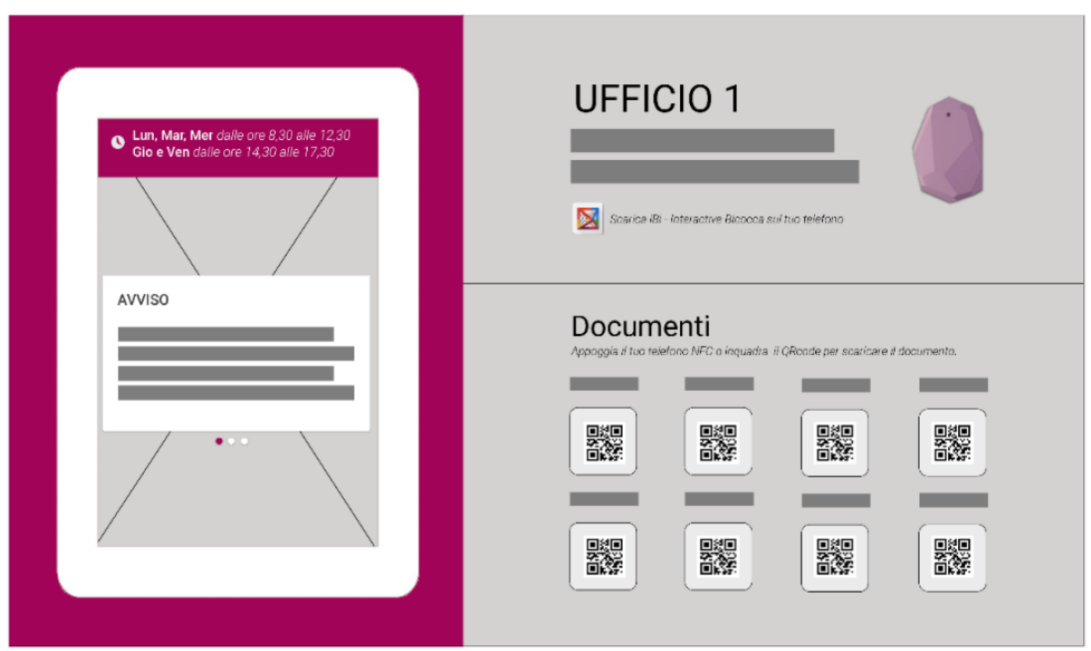

Fig. 7 Point of interest: horizontal configuration of the 3 modules (from left to right counter wise) and and related technologies: information element (tablet); contextual element (beacon), documents element (QR-Code).

\section{Designing the geobased interface of the MoBi App}

To approach the information architecture structure and to define services and contents to deliver through the application different activities of user-centered and co-design where developed.

First of all an on-line questionnaire was launched early in the design phase to understand how people of the different targets where used to search information and 
which expectation they could have on a future mobile application aimed to help people both as a student guide and as a orientation tool in the campus. 67 people took part spontaneously to the survey and 10 of them where involved in the next research activity.

A card-sorting workshop was organized to understend wich services were important for students and how organize and label them according to the user experience and expectetion.

This approach to mobile navigation was crucial to priorityze functions according to the different persona needs - newbies were less confident and they need a wider and depeer support, gurus prefers shortcuts and abbreviations - to cluster services and information and to correclty label them. This activity was revised during the iterative test-assess-redesign cycle tha broght some modification in the previous design choices (the item: "collections" becomes "to-do list" and some icons have been changed folowing the user test results).

In addition to user space tests already described, 15 subjects took parte to an A/B test on the Lo-Fi mockups to asses some of the interface spatial organization of the wire-frame and some structural components disposition.

In the next few images the interface design adopted to represent some of the spatial tasks of the application and their relation with the signage system are shown.
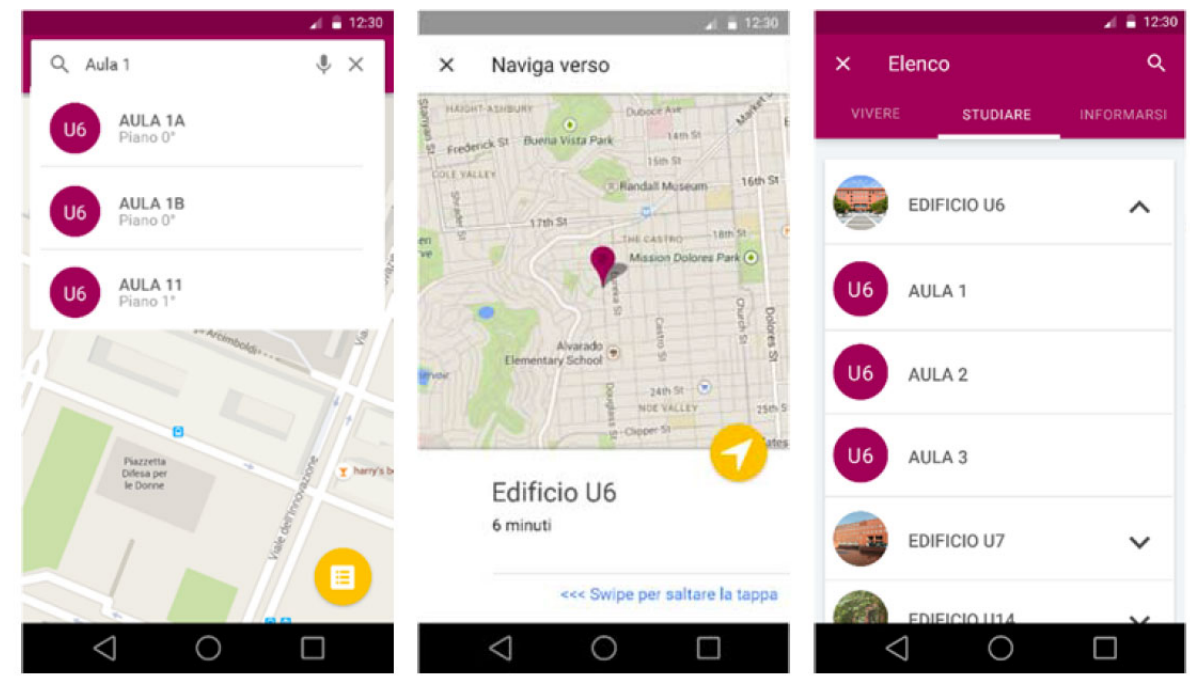

Fig. 8 MoBi app: how to locate: a. the single classroom c. inside a building and b. where the building is inside the Bicocca-Campus area 

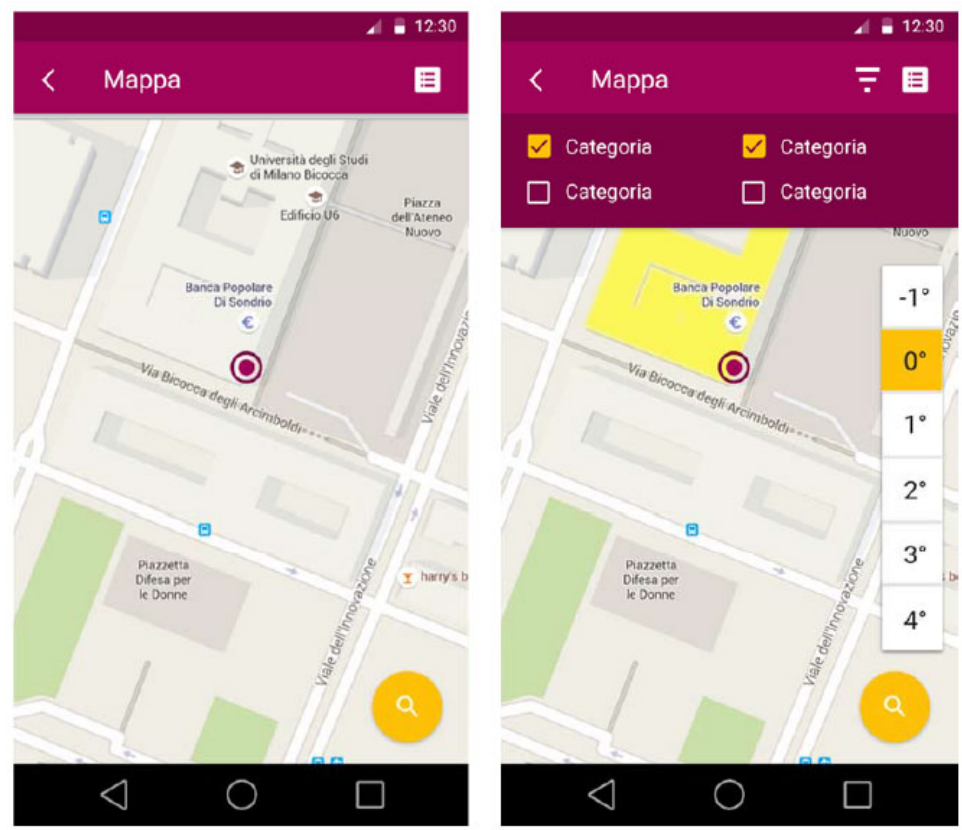

Fig. 9 MoBi app: comparing a standard georefenced visualization (on the left) and the $\mathrm{iBi} / \mathrm{MoBi}$ multilayer, filterable georefenced visualization (on the right).
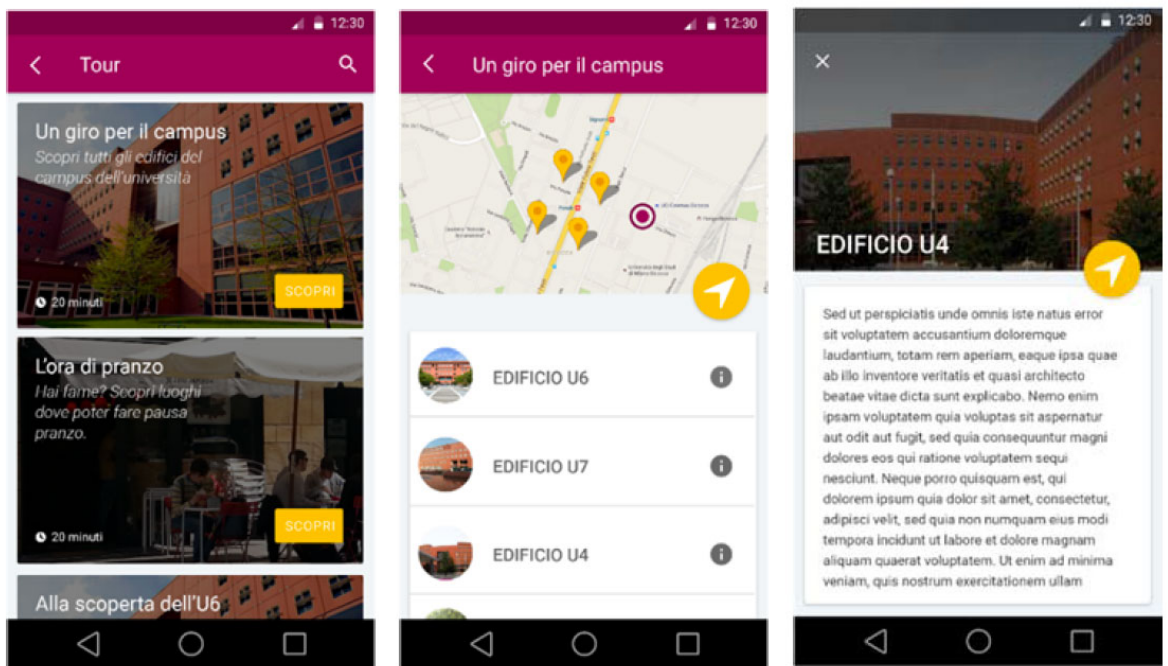

Fig. 10 MoBi app: the Tour feature designed to help newbies in the campus discover 

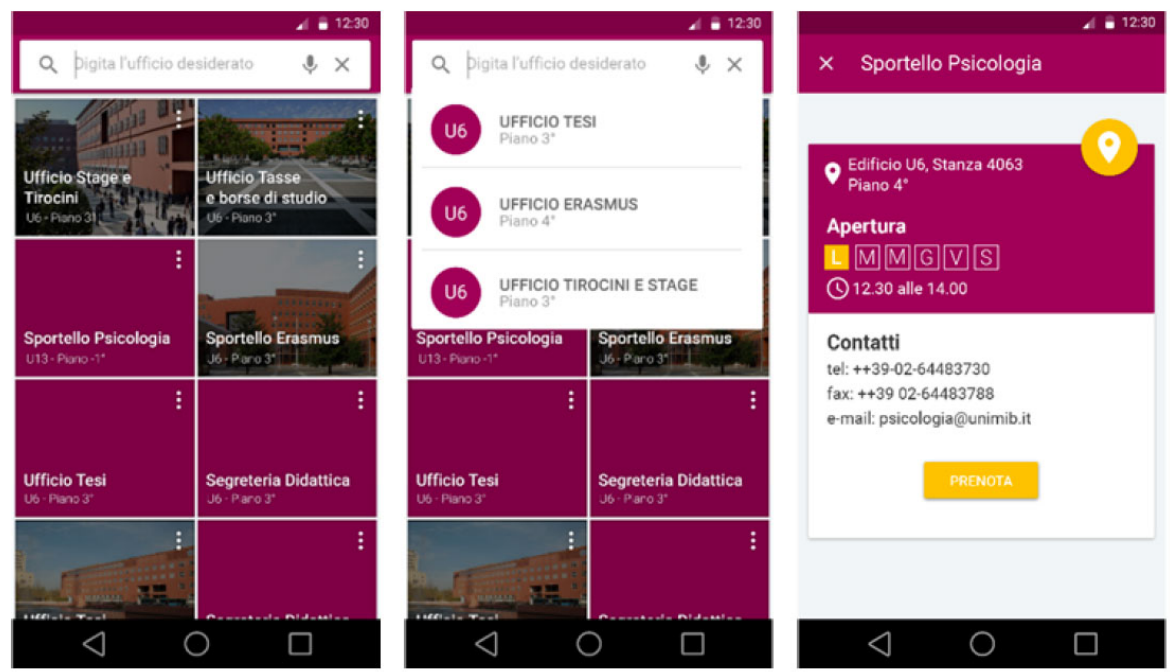

Fig. 11 MoBi app: offices' location, basic function and information, opening days/hours directly connected to module 2 of the Point of interest signal.

Interface elements have been designed according to Material design guide lines developed by Google for resident and custom applications development. The application, based on Beacon infrastructure is manly intended for Android devices - mainly used by students as emerged by the questionnaires - although further development with Beacon can be implemented for iOS target.

Other visual values and choices — such as the colour language - are intended to be coherent with the corporate image of the University institution, Further more the purple tint is the declination of the academic symbolic palette for the Psychology Department. Yellow has been chosen as accent colours thanks to the high contrast level able to guarantee a good discrimination with the primary one, its variables and neutral grey scale although in the code of gogliardia it is associated to Economical Degrees

The font used - Google font Roboto - is a third generation screen font able to guarantee a high level of legibility of the text also in bad visibility conditions (movement, dazzling lights, small dimension or display resolution and quality). Text, contents, labels and titles are black or white not to be confused with other significant elements of the interface or interactive actions triggers. They remain neutral and with the highest contrast with the interface backgrounds' colours.

\section{Physical vs. digital: comparing the way-finding tasks}

The whole project has been tested with two different finality.

Firstly it has been validated with users through a intense user-testing activity: 20 people took part to the evaluation sessions.

Task analysis: 12 tasks were proposed and tested to understand the navigation, services and an overall assessment of the application. 
System usability score: users were asked to score the application, their experience and the perceived usability using a 0-5 Lickert Scale

Semi-structured interviews and co-design workshop: critical navigation elements and screen-shot have been discussed and redesigned directly involving the users in a co-design session.

A second type of evaluation activities has been conducted to compare the previous wayfinding and orientation experience with the one mediated and supportted by the MoBi app. 12 people were involved in a dynamically session out- and in-door.

Task analysis: 3 tasks - from the easiest to the hardest according to the first phase results - were proposed and tested to understand the navigation, services and an overall assessment of the application.

System usability score: users were asked to score the application, their experience live using a 0-5 Lickert Scale

Semi-structured interviews: overall navigation and qualitative feed-back.

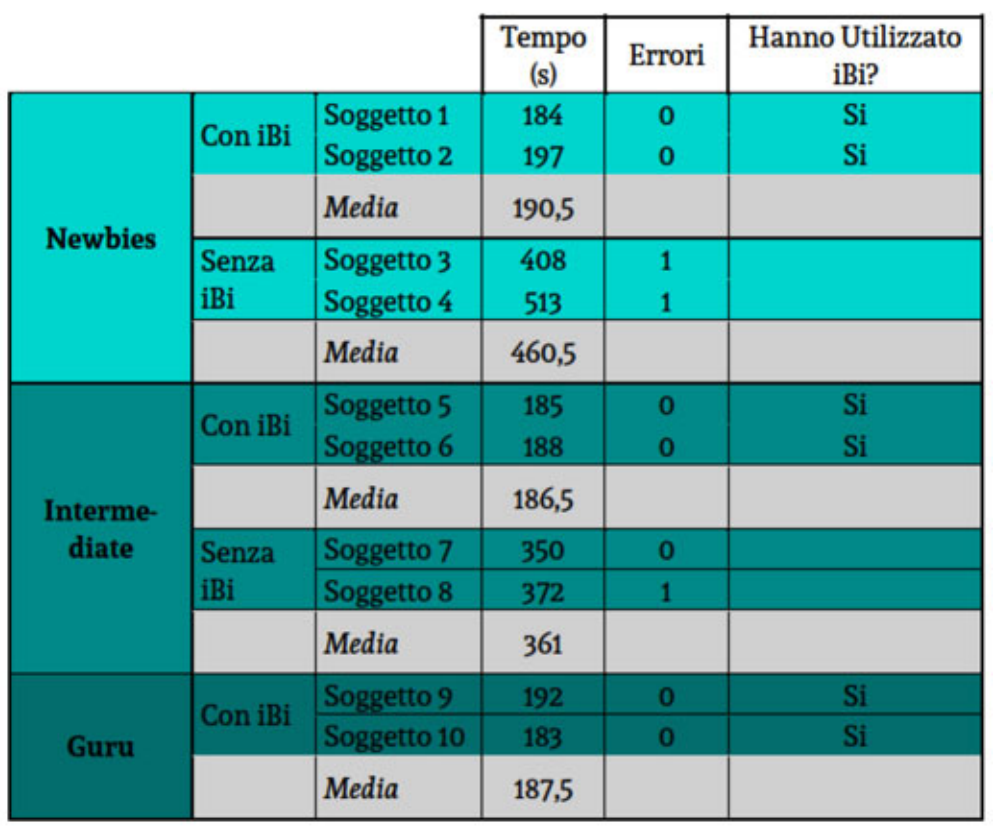

Fig. 12 MoBi app: comparing persona-based test executions with and without $\mathrm{MoBi}$ (iBi) App support: here are exemplified the task 3 results.

As figure 12 shows the coparision between smartphone + signage support + peer help experience and the MoBi support are significanlty difffferent also in quantitative terms. Time to complete the way-finding tasks are semply lower when people use the digital application. The time to complete the activity is almost halved and -as emerges from the qualitative and semi-structured interviews - the overall perception is an easy to use and helpful support. 


\section{Conclusions}

After the different validation sessions and the design assessment the project should still face some further possible improvement and development.

The experimental pilot of the $M o B i$ application should be extended to the whole Campus - buildings, services, infrastructure, departments and sub-campus - to verify the hypothesis and the complexity of the information architecture embedded in the system. A cross platform app could be tested according to iOS and windows phone requirements or a responsive web site, although this solution implies a huge unification effort of all the university digital frameworks both on line and intranet services.

Even if the project is developed and applied on a specific case study, the methodological approach proposed is intended to be replicable on other spatial scenarios.

The idea of a diffused spatial interaction with digital signage systems embedded in the physical environment is one of the more promising evolution of mobile, pocketable and wearable devices. On the other hand Internet of Things used both in commercial and cultural location will probably have a huge development in the next few years. This converging infrastructures - personal and widespread - are the next tasparent interface able to connect us and our situated interactions and information needs. Geobased technologies and user-centered design are the driver to plan and shape the the potentiality of such a scenario.

A partecipatory approach aimed to undestand social images of the space and cognitive mental models can give design tools and guideline to develop application based on the spatial aware.

Acknowledgments. The project was conducted with Matteo Cesati who developed and tested the application prototype and the (e)beacon settings for his Master Degree in Theory and Technologies of Communication dissertation: iBi-Interactive Bicocca app - progettare un'esperienza contestuale per il wayfinding spaziale e digitale and the contribution of Giulia Busdon, Matteo Cesati and Annalisa Mazzola involved in the MoBi research explorative phase in 2014.

\section{References}

1. La Cecla, F. Perdersi; l'uomo senza ambiente. Laterza: Bari (1988)

2. Fiorani, E. Grammatica della comunciaizone. Lupetti: Milano (1992)

3. Lynch, K. A. The image of the city. The MIT Press: Cambridge (1960)

4. Wurman, R. S. Making the City Observable, Design Quarterly No. 80. The MIT Press: Cambridge (1971)

5. Augé, M. Non-Lieux. Introduction à une anthropologie de la surmodernité. Le Seuil: Paris (1992)

6. Ittelson W. H. La Percezione dell'ambiente e teorie percettive. In W. H. Ittelson, (Ed.) La psicologia dell'ambiente. Franco Angeli: Milano (1973)

7. Bagnara, S. \& Misiti, R. (Eds.): Psicologia ambientale. Il Mulino: Bologna (1978)

8. Francescato D., Mebane W. How Citizens wiew two Great Cities: Milan and Rome. In Downs R., Stea D. (Eds.), Images and Environment. Aldine: Chicago (1973). 
9. Bollini, L. Territories of digital communities. Representing the social landscape of web relationships. In B. Murgante et Al. (Eds.) Computational Science and Its ApplicationsICCSA 2011, Vol. 6782: 501-511. Springer-Verlag, Berlin. (2011).

10. Bollini, L. Comunicare con il colore spazi e percorsi: Aspetti metodologici, ergonomici e user-centered. Campus bicocca: Un caso studio. In M. Rossi \& A. Siniscalco (Eds.), Colore e colorimetria. Contributi multidisciplinari, Vol. VIII: 431-438). Maggioli Editore, Santarcangelo di Romagna (RN) (2012).

11. Perkins, M. Digital natives, digital immigrants part 1. In On the horizon, 9(5), 1-6 (2001).

12. Schmidt, L., \& Hawkins, P. Children of the tech revolution. In Sydney Morning Herald. (2008).

13. Budiu, R., Nielsen, J. Mobile Usability. New Riders Press: San Francisco (2012)

14. Krug, S. Rocket Surgery Made Easy: The Do-It-Yourself Guide to Finding and Fixing Usability Problems. New Rider: san Francisco (2009)

15. Weisman, J. Evalueting Architectural Legibility: Wayfinding and the Built Environment. Environment and Behavior 13(2):189-204, p. 98 (1981)

16. Manh Hung V. et al., (2009), "Indoor Navigation System for Handheld Devices", Worcester Polytechnic Institute, Worcester, USA.

17. Dey, A.K. Understanding and Using Context. Georgia Institute of Technology, p. 2. (2001)

18. Chen G., Kotz D. A Survey of Context-Aware Mobile Computing Research. Dartmouth Computer Science Technical Report TR2000-381. Dartmouth College. (2000)

19. Schmidt A., Gellersen H.W. \& Beigl M. There is more to context than location. Computers \& Graphics. 23(6) (1999).

20. Morville, P. Ambient Findability: What We Find Changes Who We Become. O'Reilly Media: San Francisco (2005)

21. Play Store, "Google Maps Floor Plan Marker" https://play.google.com/store/apps/details?id=com.google.android.apps.insight.surveyor\&hl =it [Visited: 28 July 15]

22. Coutand, O. A Framework for Contextual Personalised Applications Kassel University Press: Kassel, pp. 21 (2009).

23. Schmidt A., Gellersen H.W., Beigl M. There is more to context than location. Computers \& Graphics, 23(6). (1999). 